\title{
LA CONSULTA PRELEGISLATIVA Y LA PARTICIPACIÓN DE LOS TITULARES DE DERECHOS COLECTIVOS: ¿MITO O REALIDAD? ANÁLISIS DEL CASO DE LA LEY DE AGUAS ${ }^{1}$ \\ DOES THE PARTICIPATION OF INDIGENOUS PEOPLE IN THE LEGISLATIVE CONSULTATION PROCESS IN ECUADOR MATTER? CASE STUDY OF WATER LAW
}

\author{
Andrés Martínez Moscoso \\ Director del Programa de Liderazgo y Gobernabilidad \\ CAF Banco de Desarrollo de América Latina \\ Universidad de Cuenca, Ecuador \\ andres.martinez@ucuenca.edu.ec \\ Víctor G. Aguilar Feijó \\ Decano de la Facultad de Ciencias Económicas y Administrativas. \\ Grupo de Investigación en Economía Regional. \\ Universidad de Cuenca, Ecuador \\ victor.aguilar@ucuenca.edu.ec
}

\begin{abstract}
Resumen
El presente artículo tiene por objeto analizar la consulta prelegislativa ecuatoriana como mecanismo de participación de los titulares de derechos colectivos, para lo cual estudia los instrumentos internacionales de derechos humanos, la jurisprudencia de la Corte IDH, la normativa interna ecuatoriana, así como la jurisprudencia constitucional. El trabajo toma como caso de estudio el proceso de aplicación de la consulta prelegislativa realizado por la Asamblea Nacional durante la aprobación de la L.O.R.H.U.A.A. (2014).

El artículo además analiza cuantitativamente los datos de participación generados durante el proceso, con el propósito de comprobar si la opinión de los consultados fue tomada en cuenta a la hora de redactar la Ley.
\end{abstract} (2014)

${ }^{1}$ Ley Orgánica de Recursos Hídricos, Usos y Aprovechamiento del Agua, L.O.R.H.U.A.A. 
Palabras Clave: Consulta prelegislativa; Consulta y participación de los Pueblos Indígenas; Derechos de los Pueblos Indígenas; Ecuador; Derecho del Agua.

\section{Abstract}

This paper focus in the analyses of Ecuadorian pre-legislative consultation like a mechanism of participation of Indigenous Peoples. The document studies the international legislation of Human Right, precedents of Interamerican Human Rights Court, and national legislation, and Constitutional Sentences. Our work take for the study case the Ecuadorian process of Pre-legislative Consultation in the project of Water of Law (2014).

The paper makes a qualitative analysis of the participation data during the process with the objective to probe if the opinion of the people which were consulted were considered in the final legislative project.

Key Words: Pre-legislative Consultation; Consultation and Participation of Indigenous Peoples; Rights of Indigenous Peoples; Ecuador; Water Law.

\section{Extended abstract}

This article analyses the role of the pre-legislative consultation process as a meaningful participatory mechanism for indigenous communities in Ecuador. This document studies the international laws, the jurisprudence created by the Inter-American Court of Human Rights and the Ecuadorian Constitutional Court rulings. Specifically, this paper takes as a case study the analysis of the consultation process related to the Water Bill taken in 2014.

This paper discusses the importance of acknowledging the indigenous collective rights and tries to establish whether the legislative consultation procedure constitutes indeed a participatory mechanism. In particular, the paper studies the participatory mechanism of the communities through the legislative consultation procedures in cases where the National Assembly (legislative body) introduces a bill that affects the collective rights. It also tries to ascertain whether the opinions of the consulted communities are considered in the approved law, given that the outcomes of the consultation process are not binding.

In order to assess the above case relative to an international benchmark, the precedents created by the Inter-American Human Rights Court are considered, given that its rulings have been considered very sensitive to the indigenous communities. These precents have had important impacts on member countries as the precedents set by the rulings have influenced signatory States to change some of their local legislation based on those rulings to protect the rights of the indigenous communities. Three key rulings are analysed: the case of the Aloeboetoe and others versus Surinam in 1991, the case of the Indigenous People Kichwa of Sarayacu versus Ecuador in 2012 and the case related to the Massacres in Rio Negro against Guatemala.

Of national policy significance, the research highlights the differences between the global perspective of indigenous groups and nationalities and the development strategy stated in the Constitution which is based on the Sumak Kasay concept or Good Living. Further, the real impact of the Constitutional Court ruling that establishes minimum requirements for the legislative consultation procedure is examined. This ruling requires all consultation pro- 
cesses to a) engage with the involved parties, and b) elaborate the phases of the process (preparation, public announcement, information and carrying out of the consultation, results analysis and closing). This research aims to establish whether or not this constitutional change has resulted in the voices of the indigenous people being heard and accounted for in legislation changes or whether the process remains a mere formality.

To asses our argument, we start reviewing the principles of law at international and local level, and then we use qualitative analysis using newspapers and periodicals during the period 22/03/2014 to 22/04/3014 that coincides with the timeframe of the consultation legislative process of the water bill. Specifically, we consider topics related to ancestral traditions; ritual and sacred places; management of ancestral matters; use and benefits; law and customs; and participation and representation in official bodies. Secondly, we analysed whether the topics brought by the indigenous communities were indeed discussed or incorporated into the bill.

The results show that the major issues bringing into the discussion by the indigenous communities were the aim and mandate of the Water National Authority, the redistribution of the current water concessions, the autonomy to manage the water supply in small communities and mining concessions near sources of fresh water.

Regarding the outcomes of the consultation process, it is proven that the opinion of the community involved was partially taken into account as inputs during the legislative discussion of the bill. In fact, other views were more predominant. However, it worries that any official inform took into consideration the alternative proposals submitted by the involved communities during the consultation process. Thus, we suggest that the National Assembly should be more forthright when choosing the topics to be consulted. Also, the legislative body should design a mechanism allowing to include in the legislative debate the alternative proposals made by the consulted communities. Otherwise, the consultation process would lose its significance and importance. We conclude saying that the legislative process is a mere formality so it seems reasonable to enact a Law regulating the consultation procedures so that the views and inputs from the communities affected will be seriously taking into account during the bill discussion.

\section{INTRODUCCIÓN}

El presente trabajo tiene por objeto estudiar el mecanismo de participación de las comunas, comunidades, pueblos y nacionalidades indígenas, afroecuatorianos y montubios a través de la consulta prelegislativa, cuando la Asamblea Nacional presente un proyecto de ley que pueda afectar los derechos colectivos de los grupos anteriormente referidos, así como comprobar su alcance y el grado en el que la opinión de los consultados es reflejada en el texto de la Ley definitiva, aunque la Consulta no sea vinculante.

Para lo cual el artículo se divide en tres grandes apartados: a) el primero, que se encarga de realizar un análisis normativo y jurisprudencial, tanto a nivel in- 
ternacional con los respectivos instrumentos internacionales y el Sistema IDH, así como a nivel nacional, para lo cual se analiza la principal normativa vigente en la materia, y de manera particular estudia la jurisprudencia constitucional de la CC del Ecuador; b) el segundo, realiza una análisis en profundidad del contenido de la consulta prelegislativa, a través de sus contenidos, requisitos básicos, principales actores que intervienen en el proceso, sus fases, al igual que se detiene y discute acerca de las fortalezas y debilidades del Instructivo para la Aplicación de la consulta prelegislativa expedido por el legislativo; y, c) el tercero y último, que toma como caso de estudio la consulta prelegislativa realizada en la aprobación de la L.O.R.H.U.A.A. (2014), siendo fundamental el análisis cuantitativo y cualitativo que se hace a partir de los resultados obtenidos en dicha Consulta a nivel provincial y que los autores se han encargado de trasladarlos a nivel nacional con el propósito de hacer una lectura global de los resultados. Del mismo modo, se brinda una visión adicional del proceso a través de un estudio de la hemeroteca de los principales diarios del Ecuador, durante el proceso de realización de la consulta prelegislativa, con el propósito de tener mayores elementos de juicio y conocer las aspiraciones de los actores, sobre todo de los colectivos indígenas y campesinos, que no necesariamente se encuentran reflejados en los resultados de la Consulta.

A lo largo del trabajo se discute acerca de la importancia que tiene el reconocimiento de los derechos colectivos de los pueblos indígenas, e intenta demostrar a través de los hechos si realmente la consulta prelegislativa es un mecanismo de participación para que los consultados pueden expresar sus expectativas, disensos y posibles malestares, con el propósito que el legislador tenga mayores elementos de juicio a la hora de normar situaciones que podrían afectar los derechos reconocidos a nivel constitucional e internacional de estos colectivos.

Por tanto, se pone en contraposición si la consulta prelegislativa se trata de un mero requisito formal, al no tener carácter vinculante, o si al contrario, las discusiones y las resoluciones, son elementos sustanciales para el debate legislativo. Todo ello puede ser visto en gran medida a través de un caso práctico, como es el caso de la L.O.R.H.U.A.A. (2014), y los respectivos porcentajes de aceptación de las propuestas, de los disensos y respectivos consensos.

\section{LOS DERECHOS COLECTIVOS}

\subsection{La Consulta Previa en los instrumentos jurídicos internacionales}

Si realizamos una retrospectiva, observamos que el reconocimiento de los Derechos de los Pueblos Indígenas ${ }^{2}$ llega décadas después de la consecución de

${ }^{2}$ El reconocimiento de los derechos colectivos de los pueblos y nacionalidades indígenas se hace gracias a una concepción mucho más amplia de los Derechos Humanos, en la cual el Estado permite y garantiza la multietnicidad y la pluriculturalidad. 
los Derechos Civiles y Políticos (1966) y los Derechos Económicos Sociales y Culturales (1966), respectivamente, y solo será efectivo a finales del siglo pasado a través del "Convenio sobre los Derechos de los Pueblos Indígenas y Tribales" (1989) de la Organización Mundial del Trabajo, OIT, en adelante Convenio 169 , del cual tan sólo 22 Estados lo han ratificado ${ }^{4}$. Y resulta interesante, que el primer reconocimiento formal se hiciese por parte de un Organismo Internacional dedicado a la defensa de los derechos laborales como la OIT.

Por otro lado, en el plano internacional merece especial atención la "Declaración de las Naciones Unidas sobre los Derechos de los Pueblo Indígenas" (2007), adoptada por la Asamblea General, a través de Resolución A7RES761/ 295; sin embargo, es necesario señalar que al tratarse de una Declaración, ésta forma parte del soft law, es decir, no vincula jurídicamente a los Estados, pero si establece el marco común sobre el cual los Estados implementan y desarrollan el reconocimiento y la protección de los pueblos indígenas. Del mismo modo, dentro del Sistema de Naciones Unidas, algunos Comités y Relatorías se han pronunciado estableciendo estándares en relación con los pueblos indígenas, así como otros dentro del Sistema Interamericano de Derechos Humanos, SIDH, e incluso se han fijado estándares por parte de organismos financieros multilaterales (Rodríguez y Morris, 2010).

Sin embargo, el Convenio 169 se encarga de esta manera de regular una serie de aspectos, entre ellos: la identificación y el respeto al derecho consuetudinario, las responsabilidades de los Estados, los territorios ancestrales, los recursos naturales, la salud y la seguridad social, la educación, etc., pero sobre todo en relación con nuestro objeto de estudio, se encarga de establecer los procesos de participación de los pueblos indígenas a través de la consulta previa, desarrollada en los artículos 6 y 7 del Convenio.

El objeto jurídico de los artículos antes mencionados, es proteger los intereses de los pueblos indígenas frente a las decisiones gubernamentales cuando éstas puedan afectar directamente los intereses de los titulares de derechos colectivos, frente a lo cual es obligación del Estado consultar a los involucrados a través de procedimientos apropiados y con las instituciones representativas de los pueblos indígenas. Para ello se debe garantizar y poner a disposición los medios para que los pueblos indígenas participen de manera libre ${ }^{5}$.

\footnotetext{
${ }^{3}$ Especial atención merece la distinción entre pueblo indígena (originarios de la zona geográfica) y pueblo tribal (no se trata de un pueblo indígena, pero que comparte características con estos, tales como tradiciones, cultura, etc.). (Abreu, 2012). Véase: Corte IDH, caso Comunidad Mayagna (Sumo) Awas Tigni contra Nicaragua, sentencia de 31 de agosto de 2001; Comunidad Moiwana contra Suriname, sentencia de 8 de febrero de 2006; y, Comunidad Indígena Yakye Axa contra Paraguay, sentencia de 6 de febrero de 2006.

${ }^{4}$ Ecuador ratificó el Convenio 169, el 15 de mayo de 1998.

${ }^{5}$ Consentimiento dado libremente (sin coerción o manipulación) y con pleno conocimiento de causa (art. 16. 2). Será la Declaración de las Naciones Unidas sobre los Derechos
} 
Además, dispone que las consultas deban realizarse de buena $\mathrm{fe}^{6} \mathrm{y}$ de una manera adecuada a las circunstancias, esto es respetando la organización de los pueblos, su lengua, su idiosincrasia, etc., siendo siempre responsable de su realización el Estado.

Mientras que el art. 7, señala algo fundamental ligado con el desarrollo, pues serán los pueblos quienes decidan las prioridades respecto a su desarrollo, teniendo en cuenta si estas afectan su vida, bienestar espiritual, territorios ancestrales, etc. (pudiendo ser la cosmovisión del Sumak Kawsay en el caso ecuatoriano).

El articulado propuesto en el Convenio 169 es de doble vía, pues no sólo permite reaccionar frente a una decisión que puede afectar sus intereses, sino que además es propositiva. El Relator Especial sobre los derechos de los pueblos indígenas, James Anaya (2009) ${ }^{7}$, señaló que los Estados tienen el deber de celebrar consultas respecto de las situaciones que afecten a los derechos colectivos de los titulares de los mismos, sin embargo, el Relator reconoce que no existe una fórmula específica para consultar a los pueblos indígenas, pues debe adecuarse a las condiciones de cada país.

Se destacan sobre todo 2 tipos de contextos en los cuales se realizan las consultas: a) respecto de iniciativas de desarrollo y extracción de recursos naturales; y, b) respecto de reformas constitucionales y legislativas relativas a temáticas indígenas, que es el caso de nuestro estudio.

Además, señaló que constituye una exigencia para los Estados el celebrar las consultas de buena fe, a fin de llegar a acuerdos o generar consentimiento ${ }^{8}$, para lo cual se deben utilizar elementos que fomenten la confianza en los titulares de derechos colectivos, ya que ello puede generar consensos ${ }^{9}$.

\subsection{Jurisprudencia de la Corte IDH}

Dentro del SIDH, uno de sus pilares fundamentales a nivel jurisprudencial es la Corte Interamericana de Derechos Humanos, Corte IDH, con sede en San José, la cual en el desarrollo de sus sentencias ha tenido una especial sensibilidad con

de los Pueblo Indígenas la que utilice la expresión "consentimiento libre (véase los artículos 5, 18, 19 y 23), previo (con antelación) e informado".

${ }^{6}$ Véase el principio pacta sunt servanda, relacionado con la buena fe aplicado en el Derecho Internacional Público en relación a los Tratados Internacionales.

${ }^{7}$ En el Informe del Relator Especial sobre la situación de los derechos humanos y las libertades fundamentales de los indígenas - Misión Ecuador (2009).

${ }^{8}$ Una de las mayores discusiones se centra precisamente si el consentimiento previo, libre e informado se trata de un proceso vinculante, o si por el contrario es una declaración de buena voluntad del Estado. Al respecto, tanto la Declaración de las Naciones Unidas sobre los derechos de los pueblos indígenas, así como la jurisprudencia de la Corte IDH, determinan los casos en los cuales es obligatoria la obtención del consentimiento. (Carrión, 2012).

${ }^{9} \mathrm{~A}$ través del respeto a los procedimientos propios para la adopción de resoluciones. 
los pueblos indígenas y tribales, pues ha considerando que estos merecen un trato y unas medidas especiales que garanticen el ejercicio pleno de sus derechos (propiedad y supervivencia social, cultural y económica, art. 1.1. Convención Americana de Derechos Humanos) (Abreu, 2012), situación que ha quedado reflejada en los casos puestos a su consideración (competencia contenciosa) por parte de la Comisión Interamericana de Derechos Humanos, CIDH, desde el año 1991 con el caso Aloeboetoe y otros contra Surinam, hasta el año $2012^{10}$ tanto con el caso del Pueblo Indígena Kichwa de Sarayaku contra Ecuador ${ }^{11}$, así como el caso Masacres de Río Negro contra Guatemala, respectivamente.

Tabla 1. La principal jurisprudencia de la Corte IDH en materia de Pueblos Indígenas ${ }^{12}$

\begin{tabular}{|c|c|c|}
\hline Añón ${ }^{13}$ & Caso & Derechos vulnerados \\
\hline $2000-2001$ & $\begin{array}{l}\text { Caso de la Comunidad } \\
\text { Mayagna (Sumo) Awas } \\
\text { Tingni Vs. Nicaragua. }\end{array}$ & $\begin{array}{l}\text { Derecho a la protección judicial. } \\
\text { Derecho a la propiedad. }\end{array}$ \\
\hline $2000-2002$ & $\begin{array}{l}\text { Caso Bámaca Velásquez } \\
\text { Vs. Guatemala. }\end{array}$ & $\begin{array}{l}\text { Derecho a la libertad personal. } \\
\text { Derecho a la integridad personal. } \\
\text { Derecho a la vida. } \\
\text { Derecho a las garantías judiciales y a la } \\
\text { protección judicial. } \\
\text { Incumplió la obligación de prevenir y } \\
\text { sancionar la tortura. }\end{array}$ \\
\hline 2004 & $\begin{array}{l}\text { Masacre Plan de Sánchez } \\
\text { Vs. Guatemala. }\end{array}$ & $\begin{array}{l}\text { Derecho a la Integridad Personal. } \\
\text { Protección de la Honra y de la Dignidad. } \\
\text { Libertad de Conciencia y de Religión. } \\
\text { Libertad de Pensamiento y de Expresión. } \\
\text { Libertad de Asociación. } \\
\text { Derecho a la Propiedad Privada. } \\
\text { Igualdad ante la Ley. } \\
\text { Protección Judicial. }\end{array}$ \\
\hline
\end{tabular}

${ }^{10}$ Mientras se escribe el presente artículo (primavera de 2015), existen 2 casos en conocimiento de la Corte IDH: Comunidad Garífuna Punta Piedra contra Honduras (2013), y Pueblos Kaliña y Lokono contra Suriname (2014).

${ }^{11}$ Sentencia completa disponible en: www.corteidh.or.cr/docs/casos/articulos/seriec_ 245_esp.pdf, última consulta: 13/05/2015.

${ }^{12}$ Las sentencias han sido seleccionadas por los autores del presente artículo en base al mérito que éstas presentan en la jurisprudencia del SIDH. La totalidad de las sentencias en relación con los Pueblos Indígenas se encuentran disponibles en: http://www.oas.org/es/cidh/ indigenas/decisiones/corteidh.asp, última consulta: 14/05/2015.

${ }^{13}$ Los años son orientativos, y corresponden tanto a la sentencia de Excepciones Preliminares, Fondo, así como interpretación reparaciones y costas. 


\begin{tabular}{|c|c|c|}
\hline Año & Caso & Derechos vulnerados \\
\hline $2005-2006$ & $\begin{array}{l}\text { Caso de la Comunidad } \\
\text { Moiwana Vs. Surinam. }\end{array}$ & $\begin{array}{l}\text { Derecho a la integridad personal. } \\
\text { Derecho de circulación y de residencia. } \\
\text { Derecho a la propiedad. } \\
\text { Derechos a las garantías judiciales y } \\
\text { protección judicial }\end{array}$ \\
\hline $2005-2006$ & $\begin{array}{l}\text { Caso Comunidad } \\
\text { Indígena Yakye Axa } \\
\text { Vs. Paraguay. }\end{array}$ & $\begin{array}{l}\text { Derechos a las Garantías Judiciales y a la } \\
\text { Protección Judicial. } \\
\text { Derecho a la Propiedad. } \\
\text { Derecho a la Vida (digna) }{ }^{14} \text {. }\end{array}$ \\
\hline $2007-2008$ & $\begin{array}{l}\text { Caso del Pueblo } \\
\text { Saramaka. Vs. Surinam. }\end{array}$ & $\begin{array}{l}\text { Derecho de propiedad. } \\
\text { Derecho al reconocimiento de la } \\
\text { personalidad jurídica. } \\
\text { Derecho a la protección judicial. }\end{array}$ \\
\hline 2012 & $\begin{array}{l}\text { Caso Pueblo Indígena } \\
\text { Kichwa de Sarayaku } \\
\text { Vs. Ecuador }{ }^{15} \text {. }\end{array}$ & $\begin{array}{l}\text { Derechos a la consulta, a la propiedad } \\
\text { comunal indígena y a la identidad cultural. } \\
\text { Derechos a la vida e integridad personal. } \\
\text { Derechos a las garantías judiciales y a la } \\
\text { protección judicial. }\end{array}$ \\
\hline
\end{tabular}

Fuente: Elaboración propia a partir de la Relatoría sobre los Derechos de los Pueblos Indígenas-OEA (2015).

Como se pudo explicar en apartados anteriores, si bien existe una normativa internacional (Convenio 169 y Declaración ONU), en el caso interamericano, la Corte IDH ha establecido un marco jurisprudencial dentro del cual los Estados parte, han desarrollado derechos y garantías a favor de los pueblos indígenas, en particular relacionado con sus territorios ancestrales y correspondientes recursos naturales (derecho de propiedad) ${ }^{16}$, así como la protección del patrimonio inmaterial (cultura y conocimientos ancestrales), entre otros, que en el caso ecuatoriano se encuentran ampliamente desarrollado en el texto constitucional.

14 "Para la Corte Interamericana, las afectaciones especiales del derecho a la salud, e íntimamente vinculadas con las del derecho a la alimentación y el acceso al agua limpia impactaban "de manera aguda el derecho a una existencia digna y las condiciones básicas para el ejercicio de otros derechos humanos, como el derecho a la educación o el derecho a la identidad cultural". Para los pueblos indígenas el acceso a sus tierras ancestrales y al uso y disfrute de los recursos naturales que en ellas se encuentran "están directamente vinculados con la obtención de alimento y el acceso a agua limpia". (Chiriboga y Donoso, 2014: 947-1026)

${ }^{15}$ Véanse los argumentos de (Anaya, 2011), sobre la consulta previa durante la audiencia Caso del Pueblo Indígena Kichwa de Sarayaku Vs. Ecuador.

${ }^{16}$ Art. 21 de la Convención Americana sobre Derechos Humanos. 


\section{ANÁLISIS NORMATIVO DE LOS MECANISMOS DE: CONSULTA PREVIA Y CONSULTA PRELEGISLATIVA EN EL ECUADOR}

\subsection{La normativa constitucional ecuatoriana}

La realidad constitucional ecuatoriana experimentó un cambio con la llegada de la autodenominada "Revolución Ciudadana", liderada por Rafael Correa Delgado, quien dentro de su propuesta de gobierno ofreció "devolver a la ciudadanía lo que era suyo", a través de un proceso constituyente, el cual fue instaurado una vez que Correa llegó al poder, y que se caracterizó por la suspensión de funciones de los diputados del entonces Congreso Nacional, y el ejercicio del legislativo por parte de la Asamblea Constituyente vía Mandatos Constituyentes con plenos poderes ${ }^{17}$, leyes, acuerdos, resoluciones y demás decisiones.

Producto de este particular período constituyente, el pueblo ecuatoriano aprobó la nueva Carta Magna, con el 63,93\% de votos, de modo que la Constitución que establece un Estado Constitucional de Derechos y Justicia, entró en vigencia el 20 de octubre de 2008, reemplazando así a aquella que en teoría se adscribía a una posición neoliberal.

Es necesario reconocer que la influencia de los diferentes actores que participaron en el proceso constituyente, dejó una importante huella de manera particular en tres ejes: a) reconocimiento de nuevos derechos de participación, dado el apoyo a Correa de los movimientos sociales; b) un nuevo concepto de soberanía, propio de una línea ideológica que responde a los intereses del Socialismo del Siglo XXI; y, c) la cosmovisión de los pueblos y nacionalidades indígenas, tanto así que el modelo de desarrollo que plantea la Constitución, se basa en el Sumak Kawsay o Buen Vivir.

De esta manera, es claro desde el propio preámbulo de la Carta Constitucional, que esta hace referencia a la Pacha Mama (Madre Tierra), apela a la sabiduría de todas las culturas, y sobre todo decide construir: "Una nueva forma de convivencia ciudadana, en diversidad y armonía con la naturaleza ${ }^{18}$, para alcanzar el buen vivir, el Sumak Kawsay.

Mientras que en el articulado, merece especial atención que al definir al Estado, se le da las características de intercultural y plurinacional, en reconocimiento a la lucha de los pueblos y nacionalidades indígenas, que ya desde la anterior Constitución (1998), hicieron presente sus reivindicaciones por su

\footnotetext{
${ }^{17}$ Art. 1, del Mandato Constituyente No. 1, 29 de noviembre de 2007.

${ }^{18}$ Véase: Espinosa Gallegos y Pérez (2011), en su obra sobre los Derechos de la Naturaleza, en la cual se hace un estudio pormenorizado sobre la particular visión del constituyente ecuatoriano de considerar sujeto de derechos a la Naturaleza en la Constitución (2008).
} 
lucha ${ }^{19}$, al reconocerlo como pluricultural y multiétnico. Situación que se refleja en el art. 2 de la CE, al reconocer al kichwa y el shuar como idiomas oficiales de relación intercultural.

En este contexto, es claro que la Constitución reserva una sección especial en el Título II, del Capítulo Cuarto, para regular los Derechos de las comunidades, pueblos y nacionalidades, así como en el Título IV, reservado a la Participación y Organización del Poder, en el Capítulo Cuarto se refiere de manera específica a la justicia indígena. En relación al tema estudiado en el presente trabajo, es necesario referirse de manera específica al art. 57, en el cual se reconoce y garantiza los derechos colectivos para las comunas, comunidades, pueblos y nacionalidades indígenas.

Como bien lo recuerda Vintimilla (2010), es necesario recordar que la Constitución prevé 3 tipos de consulta, las cuales en ocasiones se prestan a confusiones ${ }^{20}$ y que es importante distinguir: a) la Consulta previa ambiental (art. 398); b) la Consulta popular (art. 104); y, c) la consulta Previa así como la consulta prelegislativa (art. 57), objeto de nuestro análisis.

Así el numeral séptimo del mencionado articulado, se refiere a la consulta previa, mientras que el numeral décimo séptimo lo hace respecto de la consulta prelegislativa, situación que en ocasiones se confunde y se trata de manera similar, cuando realmente se refiere a derechos colectivos independientes, con características propias y efectos jurídicos distintos.

A. Consulta previa ${ }^{21}$ : Ya en 1998, la Constitución ecuatoriana, reconoció en su art. 84 a los pueblos indígenas, una serie de derechos colectivos, entre los que se encontraban en su numeral quinto, el derecho a ser consultados sobre aquellos planes, programas de prospección y explotación de recursos no renovables en las tierras de los pueblos indígenas, que pudiesen afectarles ambiental o culturalmente.

En el texto de 2008, el constituyente ecuatoriano tuvo presente las disposiciones contenidas en el art. 6 del Convenio No. 169 sobre Pueblos Indígenas y Tribales en Países Independientes, pues por primera vez al referirse a la consulta previa, se determinan sus características: a) pre-

${ }^{19}$ En 1992, a 500 años del descubrimiento de América, Ecuador vivió un importante levantamiento indígena, al cual denominaron "500 años de resistencia indígena". Véase a (Rosillo, 2012), sobre la tradición hispanoamericana de derechos humanos. La defensa de los pueblos indígenas en la obra y la praxis de Bartolomé de Las Casas, Alonso de la Veracruz y Vasco de Quiroga.

${ }^{20}$ Véase, Ley Orgánica de Participación Ciudadana y Control Social y la Ley de Minería.

${ }^{21}$ Véase (Carrión, 2012), quien realiza un amplio análisis sobre la Consulta Previa en el caso ecuatoriano. 
via; b) libre; c) informada; d) dentro de un plazo razonable. Además se señala que la misma será obligatoria y oportuna, garantizando así de manera plena los derechos colectivos, pues no sólo los reconoce, sino que determina su cumplimiento sine qua non. Eso sí, dejando a salvo que si no se obtiene el consentimiento de la comunidad, se seguirán los caminos que determine la Constitución y la ley.

B. Consulta prelegislativa: esta figura no se encuentra regulada en la Constitución de 1998, por lo que se trata de una novedosa incorporación realizada por el constituyente ecuatoriano (2007-2008) que tiene por objeto establecer un mecanismo de participación adicional a favor de las comunas, comunidades, pueblos y nacionalidades indígenas, afroecuatorianos y montubios, cuando el legislativo, Asamblea Nacional, presente un proyecto de ley que pueda afectar los derechos colectivos de los grupos antes mencionados, para lo cual se realizará la correspondiente consulta prelegislativa a fin de que los participantes, previamente inscritos, hagan saber a los legisladores los consensos así como los artículos que creyeran que pueden afectar sus derechos colectivos, a fin de que los miembros de la Asamblea Nacional los tengan presentes a la hora de aprobar o rechazar la correspondiente ley. Por lo tanto, las conclusiones alcanzadas al finalizar la consulta prelegislativa no tienen carácter vinculante, sino que sirven de insumo en favor del legislativo y como canal de participación directa del colectivo de pueblos y nacionalidades indígenas.

\section{LA SENTENCIA DE LA CORTE CONSTITUCIONAL}

La Corte Constitucional, CC, constituye el máximo órgano de control, interpretación y de administración de justicia constitucional en el Ecuador, por ello la trascendencia del estudio de su sentencia No. 001-10-SIN-CC ${ }^{22}$, de 18 de marzo de 2010, sobre la acción de inconstitucionalidad de la Ley de Minería, publicada en el Registro Oficial No. 517, de fecha 29 de enero de 2009, siendo los legitimados activos el presidente de la CONAIE, y el Presidente de los Sistemas Comunitarios de Agua, de algunas parroquias de la provincia del Azuay, en contra de la Comisión Legislativa y de Fiscalización de la Asamblea Nacional y el Presidente de la República, por atentar entre otras a los siguientes instrumentos jurídicos: a) Convenio No. 169 sobre Pueblos Indígenas y Tribales en Países Independientes, Convenio 169 de la OIT; b) Declaración de las Naciones

\footnotetext{
${ }^{22}$ Acumulación de causas: 000-8-09-IN, y 0011-09-IN. Texto completo disponible en: https://www.corteconstitucional.gob.ec/images/stories/pdfs/SUBE_Y_BAJA/SUBE_Y_BAJA 3/Sentencia_mineros.pdf , última consulta: 15/05/2015.
} 
Unidas sobre los Derechos de los Pueblos Indígenas; c) Convención Americana sobre Derechos Humanos; y, d) Pacto Internacional de Derechos Económicos, Sociales y Culturales, DESC.

Planteándose la inconstitucionalidad de fondo (art. 57 \# 7 de la de la CE) y por la forma, pues a decir de los demandantes con la norma se violó el derecho a la consulta previa prelegislativa de los pueblos y nacionalidades indígenas (derechos colectivos), así como porque las concesiones mineras se encuentran en sus territorios ancestrales, así como porque la Ley de Minería, al ser una ley ordinaria, no puede prevalecer sobre las orgánicas. La petición concreta de los demandados fue: la "declaración de la inconstitucionalidad por la forma y el fondo de la Ley de Minería"; para lo cual la CC recibió la contestación de los demandados a través de: la Comisión de Legislación y Fiscalización de la Asamblea Nacional, el Procurador del Estado y la Presidencia de la República.

En el análisis constitucional, la CC sistematizó 12 problemas jurídicos a resolver, destacando en el estudio de nuestro tema (consulta prelegislativa), aquellos consignados en los numerales: 2. (¿Cuál es la naturaleza jurídica de la consulta prelegislativa, y si se trata de un requisito de carácter formal); 4. (¿Es la consulta prelegislativa un derecho colectivo?; ¿Cuál es la diferencia entre las consultas previas reconocidas en los numerales 7 y 17 del artículo 57 de la Constitución en el proceso de aprobación de la Ley de Minería); 5. (¿Se produjo aplicación directa de las consultas previas en los artículos 57 y 398 de la Constitución en el proceso de aprobación de la Ley de Minería?); y, 6. (¿Cuáles son las reglas y procedimientos mínimos que debe contener la consulta prelegislativa prevista en el numeral 17 del artículo 57 de la Constitución).

Con respecto a la naturaleza jurídica de la consulta prelegislativa, la CC considera que la consulta constituye un derecho constitucional de carácter colectivo, no siendo tan sólo una formalidad de procedimiento legislativo.

Mientras, que si la consulta prelegislativa se trata o no de un derecho colectivo, los magistrados señalan que el art. 6 del Convenio 169 de la OIT es el marco genérico de las consultas previas, siendo esto reconocido y especificado como un derecho colectivo en la $\mathrm{CE}$, art. $57 \# 7^{23}$ y $17^{24}$, distinguiendo la Corte dos tipos de consultas.

Por lo que la consulta prelegislativa es un requisito previo sine qua non para la aprobación normativa, si ésta pudiese afectar los derechos colectivos.

\footnotetext{
${ }^{23}$ Art. 57.- Se reconoce y garantizará a las comunas, comunidades, pueblos y nacionalidades indígenas...los siguientes derechos colectivos: 7) La consulta previa, libre e informada...

${ }^{24}$ Art. 57, 17): Ser consultados antes de la adopción de una medida legislativa que pueda afectar cualquiera de sus derechos colectivos.
} 
Así también, se señala que no se debe confundir entre: a) consulta popular (art. 104 CE); b) consulta ambiental (art. 398 CE); y, c) consulta previa (derechos colectivos, art. 57 \# y \# 17).

En el examen de constitucionalidad, de manera particular en el control de fondo, se determina que durante la aprobación de la normativa impugnada (Ley de Minería), existió ausencia de un marco normativo para la realización de una consulta prelegislativa, por lo que lo que se realizó por las autoridades respectivas, fue bajo los parámetros de los Tratados Internacionales y la CE, dado el cambio circunstancial (período constituyente) que vivía el país (rebus sic stantibus).

En la Sentencia ${ }^{25}$, la CC estableció entre otras cosas, que la "consulta prelegislativa es de carácter sustancial y no formal", teniendo dicha sentencia efecto erga omnes, por lo que los requisitos básicos y el procedimiento mínimo de la consulta prelegislativa establecida por los magistrados de la CC, los cuales fueron la base para la consulta prelegislativa de la L.O.R.H.U.A.A. (2014).

\section{EL CONTENIDO DE LA CONSULTA PRELEGISLATIVA}

Hasta que el legislativo expida la ley respectiva, la CC en su sentencia No.00110-SIN-CC, en su papel de garante de los derechos, en este caso de los derechos colectivos, dictó las reglas y procedimientos mínimos en los casos de consulta prelegislativa.

Por lo que podemos decir que la sentencia antedicha reviste el carácter de una atípica, como lo reconoce la propia CC, pues "servirá de plena utilidad para el caso sub judice: las sentencias interpretativas". La Corte señala que tanto la Constitución, así como el Convenio 169 de la OIT, no definen de manera clara los parámetros para realizar la correspondiente consulta previa, ni tampoco se encuentran recogidos en normas infra constitucionales

Sin embargo, aplicando las fuentes, la CC cita la jurisprudencia de la Corte IDH, en particular el Caso Saramaca vs. Surinam, así como sentencias de la región ${ }^{26}$, recomendaciones de la OIT y del Relator Especial de ONU para los derechos de los pueblos indígenas, propias del soft law, tomando para sí los parámetros específicos desarrollados por la OIT, haciéndoles propios (fojas 53-55).

\footnotetext{
${ }^{25}$ Con el voto salvado de Nina Pacari Vega, justificado a través de un enfoque intercultural, declarando inconstitucional la Ley de Minería (2009).

${ }^{26}$ Corte Constitucional de Colombia, Sentencia C-161 de 2001; y, Tribunal Constitucional de Chile, Rol 309 de 4 de agosto de 2000.
} 


\subsection{Los requisitos básicos de la consulta prelegislativa}

De conformidad a lo que estableció la CC en su sentencia No.001-10-SIN-CC, la consulta prelegislativa debe reunir al menos los tres requisitos básicos:

Tabla No. 2. Los requisitos básicos de la consulta prelegislativa

\begin{tabular}{l|l|l|l}
\hline & \multicolumn{1}{|c|}{ Dirigida exclusivamente a: } & ¿Cuándo?: & \multicolumn{1}{c}{ ¿Por qué?: } \\
\hline PRIMERO & $\begin{array}{l}\text { Comunas, comunidades, pueblos } \\
\text { y nacionalidades indígenas. }\end{array}$ & $\begin{array}{l}\text { Antes de la } \\
\text { aprobación } \\
\text { legislativa. }\end{array}$ & $\begin{array}{l}\text { Si pudiese afectar } \\
\text { a derechos } \\
\text { colectivos. }\end{array}$ \\
\hline \multirow{2}{*}{ SEGUNDO } & \multicolumn{3}{|c}{ No se equipará a: } \\
\cline { 2 - 4 } & La consulta previa, libre e informada, ni a la consulta ambiental. \\
\hline \multirow{2}{*}{ TERCERO } & \multicolumn{3}{|c}{ Los pronciamientos: } \\
\cline { 2 - 4 } & $\begin{array}{l}\text { Se referirán a aspectos que pudiesen afectar de manera objetiva } \\
\text { derechos colectivos. }\end{array}$ \\
\hline
\end{tabular}

Fuente: Elaboración propia, a partir de Sentencia No. 001-10-SIN-CC.

\subsection{Los actores de la consulta prelegislativa}

La CC, realiza una identificación de los actores de la siguiente manera, contesta las preguntas:

a. ¿A quién se consulta?: Única y exclusivamente a las comunas, comunidades, pueblos y nacionalidades indígenas, afroecuatorianos ${ }^{27}$ y montubios $^{28}$, debiendo la Asamblea Nacional identificar previamente a los consultados $^{29}$. Durante el proceso se respetará la deliberación interna y si ésta se expresa en idioma propio, la cual deberá estar suscrita por sus representantes.

${ }^{27}$ Para Jhon Antón Sánchez (2009: 227), al referirse al caso ecuatoriano señala: “...la identidad afroamericana ha sido percibida por las élites nacionales como una marcada inferioridad, aún más que los indígenas, invisibilizada y excluida, sometida a la ideología del blanqueamiento y a pretendidas estrategias de homogeneidad mestiza nacional...".

${ }^{28}$ Según la RAE, en Ecuador y Colombia, campesino de la costa.

${ }^{29}$ Según el Censo Poblacional (2010) se auto identificaron en el Ecuador como indígenas 1.018.176 habitantes, que pertenecen a distintos pueblos y nacionalidades indígenas, que se concentran sobre todo en: a) nacionalidades indígenas 82: Tsáchila $(0,3 \%)$, Chachi $(1,2 \%)$, Epera (0,1\%), Awa (0,6\%), Kichwas (85,9\%), Shuar (9,4\%), Achuar (0,9\%), Shiwiar $(0,1 \%)$, Cofán $(0,2 \%)$, Siona $(0,1 \%)$, Secoya $(0,1 \%)$, Zápara $(0,1 \%)$, Andoa $(0,8 \%)$ y Waorani $(0,3 \%)$. b) pueblos indígenas83: Puruha (32\%), Panzaleo (14,4\%), Otavalo (13,3\%), Kayambi $(7,9 \%)$, Kañari $(6,7 \%)$, Otros $(4,8 \%)$, Saraguro (4\%), Waranka (4\%9, Tomabela $(2,8 \%)$, Karanki (2,7\%), Kisapincha (2,4\%9, Salasaca (1,5\%), Chibuleo (1,3\%), Kitukara (0,6\%), Huancavilca $(0,5 \%)$, Natabuela $(0,4 \%)$, Paltas $(0,1 \%)$, Manta $(0,1 \%)$, Pastos $(0,3 \%)$ (Martínez, 2015: 141)". 
b. ¿Quién consulta?: La Asamblea Nacional (legislativo), en colaboración con el Consejo Nacional Electoral, CNE, y el Consejo de Desarrollo de las Nacionalidades y Pueblos del Ecuador, CODENPE.

\subsection{Las fases de la consulta prelegislativa}

Al no existir una normativa que se encargue de regular la consulta prelegislativa, la CC en su sentencia estableció al menos 4 fases que deberían cumplirse para la realización de éste importante requisito sustancial (no tan sólo formal), en aquellos casos en los que la normativa discutida en el Legislativo pueda vulnerar de alguna manera los derechos colectivos.

Razón por la cual, la Asamblea Nacional ${ }^{30}$ es la responsable de la realización de la consulta prelegislativa, apoyada de otros organismos, teniendo que regirse a 4 fases: a) preparación; b) convocatoria pública; c) información y realización de la consulta; y, d) análisis de los resultados y cierre de la consulta.

Tabla No. 3. Las fases de la consulta prelegislativa

\begin{tabular}{|c|c|}
\hline \multirow{2}{*}{$\begin{array}{l}\text { I FASE } \\
\text { PREPARACIÓN DE } \\
\text { LA CONSULTA }\end{array}$} & Agenda de la consulta (identificación de temas). \\
\hline & $\begin{array}{l}\text { Documentos necesarios para la consulta, si es necesario } \\
\text { elaboración de papeletas y seguridad con el apoyo del CNE }\end{array}$ \\
\hline \multirow{3}{*}{$\begin{array}{l}\text { II FASE } \\
\text { CONVOCATORIA } \\
\text { PÚBLICA }\end{array}$} & $\begin{array}{l}\text { Se abre la consulta a los actores previamente identificados, } \\
\text { a través de una convocatoria pública. }\end{array}$ \\
\hline & $\begin{array}{l}\text { Apertura de una oficina central (Quito) y en las respectivas } \\
\text { provincias para receptar los documentos vinculados a la consulta }\end{array}$ \\
\hline & $\begin{array}{l}\text { Posterior a los } 5 \text { días laborales de realizada la convocatoria } \\
\text { pública, el CNE receptará la inscripción de los actores. }\end{array}$ \\
\hline \multirow{3}{*}{$\begin{array}{l}\text { III FASE } \\
\text { INFORMACIÓN Y } \\
\text { REALIZACIÓN } \\
\text { DE LA CONSULTA }\end{array}$} & $\begin{array}{l}\text { Entrega de la norma a consultarse a los participantes inscritos, } \\
\text { documentos para realizar consultas, y normas vigentes sobre } \\
\text { la realización de la misma. }\end{array}$ \\
\hline & $\begin{array}{l}\text { La oficina de información y recepción brindará información, } \\
\text { facilitará y estimulará la deliberación entre los participantes. }\end{array}$ \\
\hline & $\begin{array}{l}\text { Posterior a } 20 \text { días laborales, luego del cierre de las inscripciones, } \\
\text { se receptarán los documentos de consulta, con la papeleta } \\
\text { oficial de resultados, pudiendo adjuntarse además registro de } \\
\text { participantes, deliberaciones, actas, discusiones, etc. }\end{array}$ \\
\hline
\end{tabular}

${ }^{30}$ Linzan (2012), considera que el hecho que la CC en su sentencia haya establecido reglas y principios para la realización de las consultas prelegislativas, puede graficar el llamado "poder de autolimitación o automoderación", ya que pese a lo determinado por la CC, la Asamblea Nacional optó por emitir un "instructivo" propio con el propósito de realizar la consulta prelegislativa durante la discusión de otros cuerpos legales que podían afectar derechos colectivos. 


\begin{tabular}{|c|c|}
\hline $\begin{array}{l}\text { IV FASE } \\
\text { ANÁLISIS DE LOS } \\
\text { RESULTADOS Y }\end{array}$ & $\begin{array}{l}\text { Instalación de una mesa de diálogo de los actores, y otra en } \\
\text { representación del legislativo (CAL), con duración de } 20 \text { días } \\
\text { laborales, pudiendo la Asamblea Nacional extender su plazo. }\end{array}$ \\
\hline \multirow[t]{2}{*}{$\begin{array}{l}\text { CIERRE DE LA } \\
\text { CONSULTA }\end{array}$} & $\begin{array}{l}\text { Se garantizará la discusión pública de los resultados de la } \\
\text { consulta por parte de los actores y las posibles afectaciones } \\
\text { a sus derechos colectivos. }\end{array}$ \\
\hline & $\begin{array}{l}\text { Se suscribirán consensos entre las partes (primará la buena fe). } \\
\text { Si no se llegan a acuerdos, la Asamblea Nacional los pondrá de } \\
\text { manifiesto de manera explícita y motivada. } \\
\text { Alcanzados los consensos o identificadas las discrepancias, el } \\
\text { Presidente de la Asamblea Nacional declarará el fin del proceso, } \\
\text { y prestará los resultados. }\end{array}$ \\
\hline
\end{tabular}

Fuente: Elaboración propia, a partir de Sentencia No. 001-10-SIN-CC

\section{EL INSTRUCTIVO PARA LA APLICACIÓN DE LA CONSULTA PRELEGISLATIVA}

En su sentencia, la CC señaló los requisitos y el procedimiento mínimo que la Asamblea Nacional debería observar para llevar a cabo el proceso consultivo (consulta prelegislativa), en el caso en el que en la discusión de un proyecto de ley se afecten derechos colectivos, todo esto hasta que el Legislativo "emita el acto normativo definitivo".

En éste sentido, es cuestionable que la Asamblea Nacional, pese a la importancia de la participación de las comunas, comunidades, pueblos y nacionalidades indígenas, afroecuatorianos y montubios, se haya optado por la aprobación de un instructivo por parte del Consejo de Administración Legislativa, CAL, en lugar de la reforma normativa o la inclusión de este mecanismo en la Ley Orgánica de la Función Legislativa (2009).

De esta forma, el citado Consejo (CAL), aprobó el "Instructivo para la aplicación de la consulta prelegislativa, el 13 de junio de $2012^{31}$, el cual consta de 21 artículos, 4 Disposiciones Generales, 1 Disposición Transitoria Única, y 2 Disposiciones Finales, que en esencia desarrollan los requisitos básicos y fases para la realización de la Consulta Legislativa, que constan en la Sentencia No. 001-10-SIN-CC.

Es importante señalar, que el instructivo dictado por el CAL toma como fundamentos: a) el Convenio 169 sobre Pueblos Indígenas y Tribales en Países Independientes (arts. 5 y 6); b) la Declaración de las Naciones Unidas sobre los Derechos de los Pueblos Indígenas (art. 19); y, c) la CC (arts. 57, 58, 59 y 84). Así también, se hace un reconocimiento expreso a que el instructivo es pro-

\footnotetext{
${ }^{31}$ Reformado el 25 de julio de 2012, relacionado con aspectos operativos y no de fondo.
} 
ducto de la decisión de la CC, la cual determinó que la Asamblea Nacional es el órgano constitucional responsable de realizar la consulta prelegislativa, sin embargo, el CAL interpreta que debía regularse el procedimiento a través de un acto administrativo, como lo es el instructivo analizado.

El objeto del instructivo señalado en su primer artículo, es el regular el ejercicio del derecho colectivo de los titulares consagrados en la Constitución, para ser consultados antes de la adopción de una medida legislativa que podría afectar de manera objetiva sus derechos. Además, recalca que éstos podrán intervenir por sí mismos o a través de sus organizaciones representativas ${ }^{32}$.

Por su parte, la finalidad que persigue la consulta prelegislativa es la de permitir a los titulares de derechos colectivos tener la oportunidad de ser consultados, a fin de pronunciarse sobre temas específicos incluidos en el proyecto de ley que podrían vulnerar sus derechos colectivos reconocidos constitucionalmente. Par ello, según señala el art. 5 del instructivo, será en el primer debate de dicha norma, cuando la Comisión Especializada Permanente u Ocasional encargada de su tratamiento, la cual presentará ante el resto de legisladores su decisión de someter uno o varios puntos para que sean sometidos a consulta prelegislativa, situación que deberá ser aprobada por mayoría absoluta de los miembros de la Asamblea Nacional.

Por tanto, el instructivo se encarga de establecer los seis principios sobre los que la Asamblea Nacional, como órgano responsable, realizará la respectiva consulta, apoyado tanto de sus propios organismos administrativos internos, como de otras instituciones del sector público y de las propias organizaciones de los pueblos y nacionalidades indígenas.

A partir del artículo sexto del instructivo, se desarrolla el contenido de las fases de la consulta: a) fase de preparación; b) fase de convocatoria pública; c) fase de información y realización; y, d) fase de análisis de los resultados y cierre de la consulta prelegislativa), las cuales en esencia responden a las cuatro propuestas que hizo la CC en su sentencia, razón por la que el análisis aquí sólo será sobre aspectos administrativos y formales, pues el fondo se mantiene.

En la fase de preparación, los tiempos se mantienen y la identificación de temas sustantivos la hace la Comisión Especializada, los cuales deben estar debidamente fundamentados, mismos que ya no los aprueba el pleno de la Asamblea sino el CAL.

\footnotetext{
${ }^{32}$ Para la instalación de la Mesa de Diálogo Nacional de la L.O.R.H.U.A.A., se tomó en cuenta a: Confederación de Nacionalidades Indígenas del Ecuador, CONAIE, Confederación Nacional de Organizaciones Campesinas, Indígenas y Negras, FENOCIN, Consejo de Pueblos y Organizaciones Indígenas Evangélicas del Ecuador, FEINE y Federación Ecuatoriana de Indios, FEI, como organizaciones representativas de los derechos colectivos indígenas. Sin perjuicio, que otras organizaciones también participen.
} 
Tabla No. 4. Los principios a ser observados para la consulta prelegislativa

\begin{tabular}{c|c|c}
\hline $\begin{array}{c}\text { OPORTUNIDAD } \\
\text { Debe ser realizada antes } \\
\text { de la expedición de la Ley. }\end{array}$ & $\begin{array}{c}\text { PLAZO } \\
\text { RAZONABLE } \\
\text { Se respetarán los tiempos } \\
\text { de cada una de las fases, } \\
\text { en especial las } \\
\text { deliberaciones de los } \\
\text { titulares de derechos } \\
\text { colectivos. }\end{array}$ & $\begin{array}{c}\text { Tanto la Asamblea Nacional } \\
\text { así como los participantes } \\
\text { en la consulta } \\
\text { prelegislativa obrarán } \\
\text { con: a) honradez; } \\
\text { b) probidad; }\end{array}$ \\
& c) transparencia; \\
d) diligencia; \\
e) responsabilidad; \\
f) confianza; \\
g) colaboración; \\
y, h) respeto.
\end{tabular}

Fuente: Elaboración propia a partir del Instructivo para la aplicación de la consulta prelegislativa (2012)

Posteriormente, en la fase de convocatoria pública, será el Presidente de la Asamblea el responsable de difundir el contenido y el procedimiento de consulta a los titulares de derechos colectivos, a través de los medios de comunicación y en los idiomas de relación intercultural. Además se instalará una oficina central de coordinación, así como en las provincias con el objetivo de brindar información y recibir la documentación del proceso.

Al tratarse la consulta prelegislativa de un proceso de participación que se realiza durante la aprobación de una normativa, los tiempos son cortos, por lo que en la tercera fase relativa a la inscripción y definición de los sujetos de la consulta se otorga el término de 5 días, después de realizada la convocatoria para que los titulares de los derechos colectivos se inscriban, para lo cual deben presentar la documentación que acredite su representación, recibiendo éstos a su vez el formulario con los temas sustantivos de la consulta, el cronograma de la misma, y las normas utilizadas para su realización. Posteriormente se publicará el listado definitivo de los inscritos en la consulta. 
En la fase relativa a la realización de la consulta, se respetará y promoverá la discusión interna en los distintos niveles de organización de los titulares de derechos colectivos, respetando sus costumbres, tradiciones y procedimientos de deliberación y toma de decisiones.

Una vez cumplidos 20 días de haberse entregado la información, se procederá a receptar los documentos de consulta: a) formulario; b) actas con listado de participantes.

Resulta significativo el procedimiento que se da en la última fase, a través del procesamiento de resultados, que consiste en la compilación de resultados provinciales y tabulación nacional, y por otro lado, primero la instalación de las audiencias provinciales y en segundo lugar, la mesa de diálogo nacional. En el primer caso, se realizará con la presencia de los representantes titulares de derechos colectivos consultados (no más de 3), y el resto de organizaciones no participantes con la presencia de un delegado, acudirán a las audiencias públicas provinciales, a las cuales asistirán además un asambleísta de la Comisión Especializada a cargo de la consulta prelegislativa, siendo el objetivo de la audiencia "...socializar los resultados obtenidos e identificar los consensos y disensos a ser propuestos como aporte provincial en la mesa de diálogo nacional".

Mientras que en el segundo caso, una vez terminadas las audiencias provinciales, la Asamblea Nacional convocará a una mesa de diálogo nacional para discutir los resultados de la consulta prelegislativa, pudiéndose discutir tan sólo los consensos o disensos que salieron de las audiencias provinciales, tras lo cual se suscribirá el acta correspondiente. En la mesa participarán tanto los representantes de los titulares de derechos colectivos, como los asambleístas de la Comisión Especializada.

Siete días después de finalizada la mesa de diálogo nacional, será la Comisión especializada la que elaborará el informe final de los resultados de la consulta prelegislativa, que será remitida al Presidente de la Asamblea Nacional, quien será el encargado de declarar el cierre oficial de la misma.

El aporte práctico de la consulta prelegislativa radica en el hecho de que tras finalizada la misma, la Comisión Especializada incorporará tanto lo consensos como los disensos obtenidos en el informe para el segundo debate de la ley, mientras que los consensos serán incorporados de manera directa al articulado del proyecto de ley, con lo cual se puede ver claramente la participación en la construcción de la ley de los titulares de derechos colectivos (art. 20.).

\subsection{El análisis de la consulta prelegislativa a través de los medios de comunicación}

Para el análisis de la presente sección, el equipo de investigación realizó una recopilación de información de los principales medios de comunicación del 
Ecuador $^{33}$ durante la realización de la consulta prelegislativa (22-03-2014/2204-2014), con el objeto de poner de manifiesto las opiniones, consensos y disensos de los actores políticos, sociales e indígenas, a fin de contar con mayores elementos de juicio a la hora de valorar este mecanismo de participación ciudadana.

Pese a la amplia mayoría que hasta la fecha mantiene el partido de gobierno, PAIS, (100 legisladores de 137), uno de los proyectos de ley que más preocupó al bloque legislativo fue la aprobación de la "Ley Orgánica de Recursos Hídricos, Usos y Aprovechamiento del Agua", debido a las dificultades políticas y sociales presentadas durante el proceso de discusión y consulta.

A criterio de los asambleístas y sus asesores fue un proceso de trabajo maratónico, pues en menos de quince días, literalmente tuvieron que recorrer el Ecuador (territorio de 256.370 kilómetros cuadrados aproximadamente), 24 provincias, teniendo que realizar incluso audiencias simultáneas, como lo ocurrido en Cotopaxi y Carchi, respectivamente.

Si deberíamos resumir las aspiraciones de los asistentes (los pueblos y nacionalidades indígenas, el pueblo afroecuatoriano, el pueblo montubio y las comunas) durante las audiencias, podríamos señalar que fue la inclusión de la prohibición de la privatización del agua. Demanda que a nuestro criterio resultó reiterativa, ya que la propia Carta Fundamental ecuatoriana en su art. 282 prohíbe de manera expresa "... el acaparamiento o privatización del agua y sus fuentes". Lo cual, en un Estado como la República del Ecuador, que se trata de un "Estado Constitucional de Derechos y Justicia", la aplicación de la Constitución es directa e inmediata.

De la revisión de la hemeroteca de los principales diarios durante la realización de la consulta, se vio una posición innegociable por parte del colectivo indígena representado por: la Confederación de Nacionalidades Indígenas del Ecuador, CONAIE, Confederación de Pueblos de la Nacionalidad Kichwa del Ecuador, ECUARUNARI, Federación de Indígenas Evangélicos del Ecuador, FEINE, Confederación Nacional de Organizaciones Campesinas, Indígenas y Negras, FENOCIN, entre otras, con respecto a 5 "nodos conflictivos" ${ }^{34}$, que son: 1. Desprivatizar el agua; 2. Respetar las aguas sagradas y ceremoniales; 3 . Crear un Consejo Plurinacional del Agua, encargado de vigilar y planificar la gestión del agua, en oposición a la propuesta oficial de crear una Agencia de Control del Agua, misma que tendría tan sólo la "participación" de las nacionalidades

${ }^{33}$ Diarios de circulación nacional: El Universo, El Telégrafo, y El Comercio.

${ }^{34}$ Véase también la posición crítica del Foro de los Recursos Hídricos (VV.AA, 2013) relacionada con la consulta prelegislativa. Disponible en: http://www.camaren.org/files/2013/04/ consultapreleg.pdf, última consulta: 08/05/2015. 
de forma asesora y consultiva; 4. Crear un Fondo Nacional del Agua, encargado del desarrollo agrícola (distribución equitativa de agua para riego) y que se ocupe además de mediar en los conflictos de la gestión del agua (incluso con la aplicación de Justicia Indígena, la cual es reconocida por la Constitución del Ecuador); y, 5. La no intervención en las Juntas de Agua o Sistemas Comunitarios Ancestrales.

Además de estos nodos conflictivos, dentro de las preocupaciones puestas de manifiesto en los medios de comunicación por parte de la dirigencia indígena fueron trascendentales los siguientes: a) Durante el proceso de la consulta prelegislativa, el planteamiento de los pueblos consultados fue la creación de un "Consejo Plurinacional" que regule la gestión del agua, lo cual si revisamos la Ley aprobada, no fue tenida en cuenta, ya que primó el criterio que la autoridad única del agua, en su calidad de rector, la Secretaría Nacional del Agua, con adscripción directa al Ejecutivo, sin embargo, si se creó un Consejo Intercultural y Plurinacional del Agua, como parte del sistema nacional estratégico del agua; b) Uno de los reclamos constantes fue la redistribución de las actuales concesiones de agua, pues de conformidad a lo manifestado por los dirigentes indígenas "...el 64\% del caudal de agua del país se encuentra en manos del 1\% de haciendas..." (terratenientes), situación que fue tenida en cuenta por parte del legislador, ya que la Ley manda a revisar las concesiones de derechos de uso y aprovechamiento de aguas, con el propósito de identificar los casos de acaparamiento, concentración o acumulación de concesiones; c) Otra preocupación de los indígenas y campesinos, fue el respeto de sus sistemas comunitarios de agua, denominados "Juntas de Agua", ante el temor que su administración pase a manos de los gobiernos locales o en su defecto al Estado Central. Situación que fue respetada en el texto de la Ley, en particular en el art. 48 al reconocer las formas colectivas y tradicionales de gestión del agua de las comunas, comunidades, pueblos y nacionalidades, así como el reconocimiento de su autonomía financiera, administrativa y de gestión interna; y, d) Por último, existió la pretensión del "ala política" del sector indígena, liderada por Carlos Pérez Guartambel (ECUARUNARI,), quienes solicitaron la prohibición expresa de las concesiones mineras en las fuentes de agua. Situación que fue tratada con un doble estándar por parte del legislador, ya que por una parte en la sección cuarta (aprovechamiento del agua en minería), del capítulo I, del título VI del aprovechamiento del agua, se hace referencia expresa a la autorización para el aprovechamiento del agua en las actividades mineras (art. 110), sin embargo, también se habla de la protección de las fuentes de agua (art. 111), así como la devolución de las aguas utilizadas en las actividades mineras (art. 112), todo ello coordinado tanto por la Autoridad Ambien- 
tal Nacional (Ministerio del Ambiente) y la Autoridad Única del Agua (Secretaria Nacional de Agua), ambas instancias dependientes del Ejecutivo, quien ha definido como prioritarios y estratégicos un sinnúmero de proyectos mineros en el país.

\section{7. ¿FUE REALMENTE LA CONSULTA PRELEGISLATIVA UN MECANISMO DE PARTICIPACIÓN Y DE ACUERDOS EN EL CASO DE LA L.O.R.H.U.A.A. (2014)? UN ANÁLISIS CUANTITATIVO Y CUALITATIVO}

Tal como se indica en la Tabla No. 3 (Fases para la realización de la consulta prelegislativa), una de las fases determinantes del proceso, que además corresponde a la etapa final, es el análisis de los resultados y cierre de la consulta, para ello en el presente apartado pasamos al desarrollo y análisis específico de los resultados realizados en la consulta prelegislativa de la L.O.R.H.U.A.A., a fin de señalar los consensos y la identificación de discrepancias.

A nivel nacional la desagregación por provincias da como resultado el siguiente gráfico, en el cual se consolidan 5 temas consultados.

Gráfico No. 1. Los resultados provinciales de la consulta prelegislativa

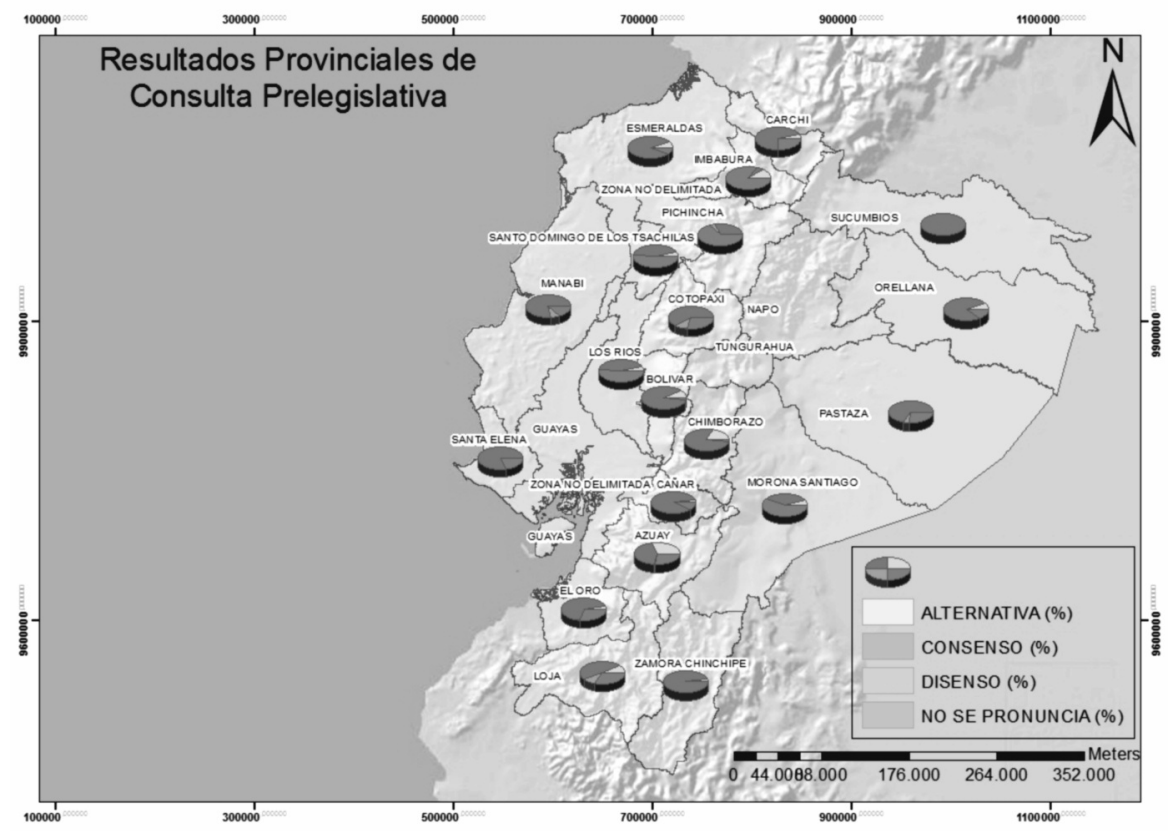

Fuente: Elaboración propia a partir de los informe de compilación de resultados provinciales (2013) 
Aquello relevante y determinante en el gráfico precedente es el elevado porcentaje de consultados que no se pronuncian en las provincias de: Santo Domingo, Morona Santiago, Los Ríos e Imbabura. En cuanto al porcentaje de disensos, las provincias de: Loja, Manabí, Pastaza y Pichincha, muestran los niveles más altos en contraste con las provincias de: Bolívar, Cañar y Sucumbíos, circunscripciones en las cuales, el consenso alcanzó cifra muy elevadas en inclusive el $100 \%$ en la última de las provincias señaladas.

En los siguientes epígrafes se presentan los análisis individualizados por cada uno de los puestos a consideración de los titulares de Derechos Colectivos a través de la consulta prelegislativa; para lo cual se analiza la información oficial (Asamblea Nacional, 2014) constantes en los distintos documentos de discusión previo a la aprobación de la L.O.R.H.U.A.A. (2014), y que han sido puestos a consideración del equipo de investigación ${ }^{35}$. Es necesario señalar que en la documentación oficial analizada, los autores han procedido a procesarla con el propósito de que los datos que se encontraban a nivel provincial, recojan ahora la información nacional, permitiendo así el estudio en términos generales para conclusiones integrales.

\subsection{Tradiciones ancestrales, lugares rituales y sagrados.}

Los temas puestos a consideración en la consulta prelegislativa, relacionado con las tradiciones ancestrales, lugares rituales y sagrados, se encuentra recogida en los artículos: 24, 41, 43, 44, 88, y 170 de la L.O.R.H.U.A.A. (2014).

Tabla No. 5. Los Resultados del

Tema I a nivel nacional

\begin{tabular}{l|c}
\hline RESULTADO DE CONSULTA & Total general \\
\hline ALTERNATIVA & $8 \%$ \\
\hline CONSENSO & $59 \%$ \\
\hline DISENSO & $2 \%$ \\
\hline NO SE PRONUNCIAN & $31 \%$ \\
\hline Total general & $100 \%$ \\
\hline
\end{tabular}

Fuente: Elaboración propia a partir de los informes de compilación de resultados provinciales (2013)

\footnotetext{
${ }^{35}$ Los autores agradecen las facilidades prestadas por D. Fernando Calderón Ordóñez, para acceder a los archivos y documentación de la Asamblea Nacional del Ecuador.
} 
Lo primero que llama la atención, al comparar los resultados a nivel nacional con el análisis que la "Comisión Especializada Permanente de la Soberanía Alimentaria y Desarrollo del Sector Agropecuario y Pesquero" realizó y que constan en el informe final ${ }^{36}$, es que en el referido documento se omitió la existencia de disensos, indicando textualmente que: “...no se registró disenso alguno sobre los contenidos sustantivos referidos a este tema". Sin embargo, aunque marginales, sí existen tales disensos, por lo que su omisión no es justificada, toda vez que además se plantearon en la consulta sobre éste tema, algunas alternativas a los artículos de referencia, así como un significativo porcentaje de consultados (titulares de Derechos Colectivos) no se pronunciaron, hecho que tampoco se recoge en el informe antes citado.

Por otro lado, tampoco es despreciable que cualitativamente no se hayan analizado casos como el de la Provincia de Pastaza, posiblemente la más rica en el recurso hídrico, en donde el disenso alcanzó el 42\%, valor que en términos generales es reducido en la integración nacional, pero que, se insiste, cualitativamente debió ser valorada de otra forma en el informe.

Por lo expuesto, el resultado final aísla las observaciones relativas a dos aspectos: a) la necesidad de que la administración y conservación de los lugares ancestrales vinculados al agua la realicen organizaciones asentadas en el mismo territorio; $y, b$ ) que se genere un inventario participativo e integral de los lugares ancestrales relacionados con el agua.

\subsection{Gestión y manejo ancestral}

Tabla No. 6. Los Resultados del

Tema II a nivel nacional

\begin{tabular}{l|c}
\hline RESULTADO DE CONSULTA & Total general \\
\hline ALTERNATIVA & $8 \%$ \\
\hline CONSENSO & $59 \%$ \\
\hline DISENSO & $2 \%$ \\
\hline NO SE PRONUNCIAN & $31 \%$ \\
\hline Total general & $\mathbf{1 0 0} \%$ \\
\hline
\end{tabular}

Fuente: Elaboración propia a partir de los informes de compilación de resultados provinciales (2013)

${ }^{36}$ Informe Final: Resultados de la consulta prelegislativa proyecto de Ley Orgánica de Recursos Hídricos, Usos y Aprovechamiento del agua, Quito, 19 de mayo de 2014 
El Tema II, relacionado con la gestión y el manejo ancestral, y que fue consultado, se relacionado con los siguientes artículos de la L.O.R.H.U.A.A. (2014): arts. $17,23,33,35,37,38,40,56,63,66,69,101,112,117,159$, yl63

Con respecto al análisis de los resultados de la consulta del tema II, pese a que el porcentaje de disenso no es superior al registrado para el primer tema, el informe final y su alcance registran disensos en los siguiente artículos: 27, 33, 101 y 163. Razón por la cual no es posible determinar con qué criterio o criterios el legislador comisionado decidió incluir o no un determinado disenso, sin embargo, queda claro que la relatividad numérica no lo fue.

\subsection{Uso, usufructo y administración}

El Tema III, que consultó sobre el uso, usufructo y administración del agua, mantiene relación con los siguientes artículos de la L.O.R.H.U.A.A. (2014): arts. $6,8,26,27,67,86,93,136,176$, y 178

Tabla No. 7. Los Resultados del

Tema III a nivel nacional

\begin{tabular}{l|c}
\hline RESULTADO DE CONSULTA & Total general \\
\hline ALTERNATIVA & $13 \%$ \\
\hline CONSENSO & $62 \%$ \\
\hline DISENSO & $1 \%$ \\
\hline NO SE PRONUNCIAN & $23 \%$ \\
\hline Total general & $100 \%$ \\
\hline
\end{tabular}

Fuente: Elaboración propia a partir de los informes de compilación de resultados provinciales (2013)

Durante la fase de la consulta prelegislativa que se encargó de preguntar sobre el tema del uso y usufructo del líquido vital, se encontró un alto porcentaje de consenso, nuevamente un muy bajo porcentaje de disenso y unos porcentajes no despreciables de no pronunciamiento y propuestas alternativas a los articulados puestos en cuestión.

Al momento de analizar los informes puestos a consideración ante el pleno de la Asamblea Nacional, se mencionan que en los artículos 7, 27 y 93 no se llegaron a consensos de manera parcial. Es importante destacar que, los disensos tienen que ver con el acaparamiento del recurso hídrico, uso de aguas termales y minerales, así como a quién corresponde fijar la tarifa, la gratuidad, así como la cantidad (volumen) de agua dentro del margen vital y gratuidad por el uso de agua para riego. Y fue precisamente que a partir de esos disensos se plantearon alternativas a los textos por parte de los consultados. 


\subsection{Derecho propio o consuetudinario}

El Tema IV, que consultó sobre el derecho propio o consuetudinario, mantiene relación con los siguientes artículos de la L.O.R.H.U.A.A. (2014): arts. 38, 42 150, 152, 205, y 207.

Tabla No. 8. Los Resultados del Tema IV a nivel nacional

\begin{tabular}{l|c}
\hline RESULTADO DE CONSULTA & Total general \\
\hline ALTERNATIVA & $9 \%$ \\
\hline CONSENSO & $64 \%$ \\
\hline DISENSO & $4 \%$ \\
\hline NO SE PRONUNCIAN & $23 \%$ \\
\hline Total general & $100 \%$ \\
\hline
\end{tabular}

Fuente: Elaboración propia a partir de los informes de compilación de resultados provinciales (2013)

El tema IV, se diferencia de los resultados hallados en los tres casos anteriores, pues en éste se encuentra el porcentaje más alto de disenso (4\%). Conforme el informe final, este 4\% implica el disenso en la modificación de la concesión por caudal por concesión condicionada a estacionalidad, lluvias, altitud y disponibilidad del líquido y a la priorización para actividades productivas.

\subsection{Participación y representación en los organismos oficiales}

El último consultado, Tema $\mathrm{V}$, corresponde a la participación y representación en los organismos oficiales, manteniendo una relación con los siguientes artículos de la L.O.R.H.U.A.A. (2014): arts.12, 58, 61, 78, 175, 225, 226, 231, 233, y 234.

Tabla No. 9. Los Resultados del

Tema IV a nivel nacional

\begin{tabular}{l|c}
\hline RESULTADO DE CONSULTA & Total general \\
\hline ALTERNATIVA & $9 \%$ \\
\hline CONSENSO & $66 \%$ \\
\hline DISENSO & $2 \%$ \\
\hline NO SE PRONUNCIAN & $24 \%$ \\
\hline Total general & $100 \%$ \\
\hline
\end{tabular}

Fuente: Elaboración propia a partir de los informes de compilación de resultados provinciales (2013) 
El porcentaje de consenso más elevado en la consulta prelegislativa se encuentra en este último tema, pues dos tercios de los consultados consensuaron con los textos propuestos por el legislador. Un único disenso se señala en el informe final, y se refiere a la necesidad de que el Consejo plurinacional y pluricultural participe de la formulación de políticas, asumiendo que la rectoría a través de la Autoridad Única del Agua, sea llevada directamente por el Estado.

\subsection{Análisis de la inclusión de disensos y alternativas en el texto final de la ley}

Aunque la consulta prelegislativa, como se ha mencionado reiteradamente, no es vinculante, es cierto que en su espíritu busca proveer de insumos al legislador para la toma de decisiones, en la medida en la que éste pueda discernir entre aspiraciones particulares y en el mejor de los casos grupales (partidarias), frente a los beneficios colectivos o generales. Al respecto, no se puede olvidar la opinión del Relator Especial, James Anaya (2010: 20), quien al referirse al caso ecuatoriano, señaló que: "El Estado debe tomar en cuenta las propuestas hechas por CONAIE durante las mesas de diálogo, así como cualesquiera otras nuevas propuestas de reforma, incluyendo en relación con la... Ley de Recursos Hídricos...y otras leyes, así como para reformar e implementar las leyes conforme a los derechos de los pueblos indígenas".

A la luz de la descripción anterior, y a los cuadros precedentes, pasamos a analizar la medida en la que los disensos y consecuentemente las alternativas, fueron reflejadas en la versión final de la L.O.R.H.U.A.A. (2014):

a. Prohibición de privatización. (art. 6). El primer disenso sobre este artículo se plantea en torno a la liberalización de las fuentes de agua en zonas de concesión minera, prohibición de extractivismo en lugares de recarga hídrica y fuentes de agua ${ }^{37}$. El segundo disenso se refiere a la mercantilización y acaparamiento de agua. El artículo mencionado, en su texto final recoge las necesidades de los consultados prohibiendo cualquier tipo de privatización, apropiación y evitando cualquier forma de mercantilización, siendo su gestión exclusivamente pública o comunitaria.

b. Cantidad vital y tarifa mínima. (art. 27). En la ley este tema se regula en el artículo 59, al respecto se plantearon dos disensos: a) Los sistemas comunitarios deben ser quienes fijan las tarifas, y no la autoridad nacional del agua $y, b)$ la cantidad vital del agua debe ser gratuita y no sujetarse a una tarifa sostenible y diferenciada. Sin embargo, en la

\footnotetext{
${ }^{37}$ Art. 110. Autorización de aprovechamiento del Agua en Minería, y art. 111. Protección de fuentes de agua.
} 
L.O.R.H.U.A.A. se regula que sea la Autoridad Única del Agua quien defina la cantidad vital de agua por persona, agua cruda que será gratuita, siempre que no sobrepase la cantidad mínima y sobre esa cantidad se determinará una tarifa sostenible y diferenciada. Por lo tanto, el planteamiento de los consultados fue recogido parcialmente en la ley.

c. Almacenamiento del agua (art. 33). El pedido de los consultados fue que el almacenamiento de aguas lluvia sea de hasta 200 metros cúbicos y que su ajuste sea técnico en virtud del régimen de lluvias en distintas zonas del país. En el texto de la ley, el artículo que lo regula es el 63, el cual señala que cualquier persona podrá almacenar agua lluvia (en aljibes, cisternas, albarradas, pequeños embalses) para fines domésticos y de riego para soberanía alimentaria, siempre y cuando no perjudique a terceros y afecte la cantidad y calidad de los cauces, dejando nuevamente que sea la Autoridad Única del Agua, la que defina el volumen de agua que se pueda almacenar.

d. Políticas en relación al agua (art. 58). El disenso en la consulta prelegislativa se enmarcó en la definición clara de las facultades que debían poseer las juntas de agua potable y riego en la gestión comunitaria del agua. Efectivamente, el artículo llevado a consulta no define las facultades de la juntas de agua potable y riego, se limitó a enlistar la orientación de las políticas, entre las cuales no se mencionaron la facultades de las juntas. En el texto final las políticas en relación con el agua se recogen en el artículo 83, mientras que la única referencia al respecto, se encuentra contenida en el artículo 49 , el cual indica que las juntas de agua mantienen su autonomía de gestión y suficiencia financiera sin especificar sus facultades en forma detallada. La ley por tanto no recoge la aspiración de los consultados.

e. Orden y prioridad para actividades productivas (art. 93). La consulta prelegislativa tuvo como resultado en este punto la petición de modificar el orden y prioridad del agua para actividades productivas. En concreto, el orden requerido por los consultados fue: a) turismo; b) hidroelectricidad; c) riego para exportación; d) balneoterapia; e) envasado de agua; y, f) actividades extractivas. El texto final (artículo 94) en la ley siguen el siguiente orden: a) riego para producción agropecuaria, acuicultura y agroindustria para exportación; b) turismo; c) hidroelectricidad; d) proyectos de sectores estratégicos e industriales; e) balneoterapia y envasado de agua; y, f) otras actividades productivas. Por lo tanto, no fue acogida la petición pues las actividades fueron agrupadas y modificadas. 
f. Aprovechamiento del agua para envasarla (art. 104). La ley señala en el art. 105, que para el aprovechamiento productivo (envasado), se requiere una autorización otorgada por la Autoridad Única del Agua, pudiendo aprovecharse de la misma tanto personas naturales, jurídicas, públicas, privadas, comunitarias, mixtas y de la economía popular y solidaria.

g. Tarifa cero para riego, como sustento para soberanía alimentario (art. 163). La observación que recogen los informes preparados para conocimiento de la Asamblea señalan como disenso la necesidad, de acuerdo a los grupos consultados, de que se fije una tarifa cero por el servicio de riego para soberanía alimentaria. En el texto aprobado, el artículo 141, enlista los criterios para la fijación de una tarifa para uso de agua para riego que garantice la soberanía alimentaria, y exceptúa de pago a los sistemas comunitarios siempre que reciban caudales inferiores a 5 litros por segundo y que estén vinculados a actividades productivas. Por lo tanto, en la medida general (para todo individuo que use el líquido para riego) no se acogió la petición de los titulares de derechos colectivos, pero si se asignó mediante la ley, la tarifa cero para sistemas comunitarios que cumplan con los criterios descritos.

h. Sobre el Consejo Plurinacional y Pluricultural del Agua (art. 225). Se plantearon como disenso, dos posiciones: a) que el Consejo Plurinacional y Pluricultural del Agua sea parte de la Autoridad Única del Agua, es decir del ente rector; y, b) que la Autoridad Única del Agua sea ejercida por el Estado y que el Consejo Plurinacional y Pluricultural del Agua cumpla funciones consultivas participativas en la formulación de políticas públicas y el seguimiento de su cumplimiento a nivel nacional. La ley recoge esta discusión en el artículo 15 y siguientes, en los cuales se crea el Sistema Nacional Estratégico del Agua, en el cual, el Consejo Plurinacional y Pluricultural del Agua es uno de sus seis miembros con atribuciones para ejercer el control social del agua, participar en la evaluación y formulación de políticas públicas, dirección y seguimiento del Plan Nacional de Recursos Hídricos, generar debates públicos sobre la gestión del recurso entre otras.

\section{PRINCIPALES CONCLUSIONES}

A continuación nos permitimos extraer las que a nuestro criterio son las principales conclusiones, que podrán ser tomadas como oportunidad de mejora en siguientes procesos, pero también se insertan críticas a los actores para que omisiones, deslices o debilidades no se vuelvan a repetir. 
Ha quedado demostrada la importancia que tienen los instrumentos jurídicos nacionales e internacionales, así como la jurisprudencia, respecto a los titulares de Derechos Colectivos (Pueblos Indígenas), frente a las decisiones gubernamentales, así como la obligación que tiene el Estado de consultar a los involucrados a través de procedimientos apropiados y con fundamento en las instituciones representativas de los pueblos indígenas, siendo importante señalar la inclusión de los afroecuatorianos y montubios para el caso ecuatoriano. Del mismo modo, el papel que ha jugado el Sistema IDH, y en particular la Corte IDH, ha sido fundamental pues ha generado un marco jurisprudencial propicio para la protección de este colectivo, sin embargo, más allá de los reconocimientos en el texto normativo o en las sentencias, la exclusión que sufren los Pueblos Indígenas aún es evidente, razón por la cual se debe pasar del frío texto de la Ley a la acción en el campo, a través del desarrollo de políticas y programas inclusivos, que tengan en cuenta la multiculturalidad y la plurinacionalidad.

A nuestro criterio, es necesario aprobar una Ley Orgánica que regule tanto la Consulta Previa, así como la consulta prelegislativa, pues ésta se ocuparía del ejercicio de derechos y garantías de las comunas, comunidades, pueblos y nacionalidades indígenas, afroecuatorianos y montubios, en la que, por supuesto, se tome como fundamento la sentencia de la Corte Constitucional, y se recoja la finalidad que tiene la misma, así como los principios a ser observados (oportunidad, plazo razonable, buena fe, interculturalidad y plurinacionaldad, e información veraz y suficiente).

Además, gracias al análisis de la hemeroteca nacional durante el período de la consulta prelegislativa, se pudo comprobar que entre las mayores preocupaciones de los dirigentes indígenas se centraron en la concentración de funciones que tendría la Autoridad Única del Agua en manos del Ejecutivo, la redistribución de las concesiones, y el respeto y autonomía de sus sistemas comunitarios de agua. Así también, el rechazo a las concesiones mineras en las fuentes de agua, lo cual tiene una mayor connotación teniendo en cuenta que la minería a gran escala forma parte de los proyectos estratégicos del gobierno de Correa Delgado.

Con respecto a los resultados de la consulta, se pudo comprobar que las opiniones de los consultados cumplieron en parte con su tarea de ser insumos para el debate al interior de la Asamblea. Del mismo modo, se observó un claro predominio de los consensos sobre otras posibilidades. Sin embargo, lo que preocupa es que en ningún informe analizado (preliminar, definitivo o alcance), se tomó en consideración las alternativas planteadas por los consultados durante el proceso de consulta prelegislativa, por lo que concluimos que la 
Asamblea se limitó a discutir únicamente los disensos y no consideró en el debate legislativo las alternativas propuestas por los grupos consultados. Por lo cual a futuro, sugerimos que la Asamblea Nacional debe tener mayor prolijidad y rigidez a la hora de escoger los temas a ser consultados, así como diseñar un mecanismo que permita incluir en el debate parlamentario, no sólo los datos estadísticos de consenso o desaprobación, sino también aquellas propuestas y textos alternativos realizadas por los pueblos consultados, caso contrario de nada serviría el pronunciamiento de estos en las distintas mesas de diálogo, desvirtuándose así el objeto de la consulta prelegislativa.

\section{BIBLIOGRAFÍA Y LITERATURA BÁSICA CONSULTADA}

Abreu Blondet, R. (2012). "Medio ambiente, derechos colectivos, consulta previa y ejercicio de derechos humanos por personas jurídicas". Anuario de Derecho Constitucional Latinoamericano, Año XVIII, 187-200.

Anaya, J. (2011). "La norma de consulta previa. Introducción a peritaje ante la Corte Interamericana de Derechos Humanos". Caso Sarayaku. San José: Corte Interamericana de Derechos Humanos.

(2013). "El deber estatal de consulta a los pueblos indígenas dentro del Derecho Internacional". Lima: Conferencia "El rol de los Ombudsman en América Latina: El derecho a la consulta previa a los pueblos indígenas".

Antón Sánchez, J. (2009). "Derechos colectivos y pueblo Afroecuatoriano". En Ávila Ordóñez, M.P. y Corredores Ledesma, M.B. (Eds.). Los Derechos Colectivos. Hacia una efectiva comprensión y protección. Quito: Ministerio de Justicia y Derechos Humanos, 217-254.

Ávila Linzan, L.F. (Ed.) (2012). Repertorio constitucional 2008-2011. Quito: Corte Constitucional para el Período de Transición.

Ávila Ordóñez, M.P. y Corredores Ledesma, M.B. (Eds.) (2009). Los Derechos Colectivos. Hacia una efectiva comprensión y protección. Quito: Ministerio de Justicia y Derechos Humanos.

Benavides Ordóñez, J. y Escudero Sóliz, J. (Coords.) (2013). Manual de justicia constitucional ecuatoriana. Cuadernos de trabajo 4. Quito: Corte Constitucional del Ecuador.

Carrión, P. (2012). Análisis de la consulta previa, libre e informada en el Ecuador. Quito: Konrad-Adenauer-Stiftung y Centro Ecuatoriano de Derecho Ambiental (CEDA).

Chacón, H y otros (2011). Participación Social, Políticas Públicas y Desarrollo. Cuenca: Departamento de publicaciones de la Facultad de Ciencias Económicas y Administrativas de la Universidad de Cuenca.

Espinoza Gallegos-Anda, C. y Caicedo Tapia, D. (Eds.) (2009). Derechos Ancestrales. Justicia en Contextos Plurinacionales. Quito: Ministerio de Justicia y Derechos Humanos. 
, y Pérez Fernández. C. (Eds.) (2011). Los Derechos de la Naturaleza y la Naturaleza de sus Derechos. Quito: Ministerio de Justicia y Derechos Humanos.

Francés, F y otros (2014). El proceso de medición de la realidad social: la investigación a través de encuesta. Cuenca: PYDLOS.

García, N. (2009). Legislar para todas. México: Colegio de Jalisco.

García-Escudero Márquez, P. y otros (2014). Manual de Técnica Legislativa. Quito: Asamblea Nacional del Ecuador.

González Casanova, P. (Comp.) (1985). Historia Política del Campesinado Latinoamericano. México: Siglo XXI Editores.

Grueso Castelblando, L.R. (2008). El Derecho de los Pueblos Indígenas a la Consulta Previa, Libre e Informada. Una guía de información y reflexión para su aplicación desde la perspectiva de los Derechos Humanos. Bogotá: Oficina del Alto Comisionado para los Derechos Humanos - Colombia.

Martínez Moscoso, A. (2015). La prestación del servicio público de agua potable en el municipalismo ecuatoriano durante la "Revolución Ciudadana" 2007-2013. Tesis Doctoral. Alicante: Universidad de Alicante.

Organización Internacional del Trabajo. (2009). Los Derechos de los Pueblos Indígenas y Tribales en la Práctica. Una guía sobre el Convenio Núm. 169 de la OIT. Lima: Organización Internacional del Trabajo.

Pérez Bouron, H. (2007). Manual de Técnica Legislativa. Buenos Aires: Konrad-Adenauer-Stiftung.

Porras Velasco, A. y Romero Larco, J. (2012). Guía de Jurisprudencia Constitucional Ecuatoriana. Período octubre 2008- diciembre 2010. Tomo II. Quito: Corte Constitucional para el Período de Transición.

Rodríguez Garavito, C. y Morris, M.(Dir.) (2010). La consulta previa a los pueblos indígenas. Los estándares del derecho internacional. Bogotá: Universidad de los Andes, Facultad de Derecho. Programa de Justicia Global y Derechos Humanos.

Rosillo, A. (2012). La tradición hispanoamericana de derechos humanos. La defensa de los pueblos indígenas en la obra y la praxis de Bartolomé de Las Casas, Alonso de la Veracruz y Vasco de Quiroga. Quito: Corte Constitucional del Ecuador.

Ruiz Chiriboga, O. y Donoso, G. (2014). "Pueblos Indígenas y la Corte Interamericana: Fondo y Reparaciones". En Steiner, C. y Uribe, P. (Eds.). Convención Americana sobre Derechos Humanos. Comentario. La Paz: Fundación Konrad Adenauer, 947-1026,

Toro Huerta, I.D. (2008). "Los aportes de la jurisprudencia de la Corte Interamericana de Derechos Humanos en la configuración del derecho de propiedad colectiva de los miembros de comunidades y pueblos indígenas". SELA (Seminario en Latinoamérica de Teoría Constitucional y Política) Paper 58, 1-24.

Vintimilla, J. (2010). "La consulta previa en Ecuador: ¿Un derecho colectivo justiciable o una mera formalidad administrativa?". Revista de la Fundación para el Debido Proceso Legal, DPLF, No. 14, 21-23. 
VV.AA. (2009). Los Derechos de los Pueblos Indígenas y Tribales en la práctica. Una guía sobre el Convenio Núm. 169 de la OIT. Lima: Departamento de Normas Internacionales del Trabajo, OIT.

VV.AA. (2013). La Consulta prelegislativa sobre el proyecto de Ley de Aguas: una oportunidad para solucionar viejos problemas. Quito: Foro de los Recursos Hídricos. Disponible en: http://www.camaren.org/files/2013/04/consultapreleg.pdf, última consulta: 08/05/2015.

\section{Normativa ecuatoriana consultada}

Constitución de la República del Ecuador (1998), 11 de agosto de 1998, Registro Oficial No. 1.

Constitución de la República del Ecuador (2008), 20 de octubre de 2008, Registro Oficial No. 449.

Ley Orgánica de la Función Legislativa, aprobada el 27 de julio de 20009, en el Suplemento del Registro Oficial No. 642.

Ley Orgánica de Recursos Hídricos, Usos y Aprovechamiento del Agua, aprobada el 6 de agosto de 2014, en el Segundo Suplemento del Registro Oficial No. 305.

Ley de Minería, aprobada el 29 de enero de 2009, en el Registro Oficial No. 517.

Sentencia No. 001-10-SIN-CC, Casos No. 0008-09-IN y 0011-09-IN (Acumulados), Corte Constitucional del Ecuador, de 18 de marzo de 2010.

Proyecto de Ley Orgánica de Recursos Hídricos, Usos y Aprovechamiento del Agua (2012). Documento utilizado para la Convocatoria a la Consulta prelegislativa. Asamblea Nacional del Ecuador.

Instructivo de Aplicación de Consulta prelegislativa. Publicado en el Registro Oficial No. 733, de 27 de junio de 2012. Consejo de Administración Legislativa. Asamblea Nacional del Ecuador.

Informe de la Compilación de Resultados Provinciales de la Consulta prelegislativa del Proyecto de la Ley Orgánica de Recursos Hídricos, Uso y Aprovechamiento del Agua, de conformidad a lo estipulado en el artículo 16 del Instructivo para la Aplicación de la Consulta prelegislativa (Codificado). Quito: 19 de abril de 2013. Comisión Especializada Permanente de Soberanía Alimentaria y Desarrollo del Sector Agropecuario y Pesquero. Asamblea Nacional del Ecuador.

Informe Final: Resultados de la Consulta prelegislativa. Proyecto de Ley Orgánica de Recursos Hídricos, Usos y Aprovechamiento del Agua. Quito: 19 de mayo de 2014. Comisión Especializada Permanente de la Soberanía Alimentaria y Desarrollo del Sector Agropecuario y Pesquero. Asamblea Nacional del Ecuador.

Alcance al Informe para Segundo Debate sobre el Proyecto de Ley Orgánica de Recursos Hídricos, Usos y Aprovechamiento del Agua, en relación a la Consulta prelegislativa. Quito: 27 de mayo de 2014. Comisión Especializada Permanente de la Soberanía Alimentaria y Desarrollo del Sector Agropecuario y Pesquero. Asamblea Nacional del Ecuador. 
Normativa e informes internacionales consultados

Anaya, J. (2009). Informe del Relator Especial sobre la situación de los derechos humanos y las libertades fundamentales de los indígenas. Nueva York: Asamblea General de Naciones Unidas.

(2010). Informe del Relator Especial sobre la situación de los derechos humanos y las libertades fundamentales de los indígenas. Observaciones sobre los avances y desafíos en la implementación de las garantías de la Constitución Política del Ecuador sobre los derechos de los pueblos indígenas. Nueva York: Asamblea General de Naciones Unidas.

(2013). Informe del Relator Especial sobre los derechos de los pueblos indígenas. Las industrias extractivas y los pueblos indígenas. Nueva York: Asamblea General de Naciones Unidas.

Normas y jurisprudencia del Sistema Interamericano de Derechos Humanos (2010). DERECHOS DE LOS PUEBLOS INDÍGENAS Y TRIBALES SOBRE SUS TIERRAS ANCESTRALES Y RECURSOS NATURALES. Washington: Organización de los Estados Americanos y Comisión Interamericana de Derechos Humanos. Disponible en: http://cidh.org/countryrep/TierrasIndigenas2009/Tierras-Ancestrales.ESP.pdf

Andrés Martínez Moscoso es Doctor en Derecho, Estudios Políticos y Constitucionales (PhD), Universidad de Alicante. Máster en Liderazgo y Dirección de Instituciones Político-Administrativas. Máster en Protección Internacional de los Derechos Humanos, y Especialista en Derecho Constitucional. Profesor en la Universidad de Cuenca. Director del Programa de Liderazgo y Gobernabilidad, CAF.

Victor G. Aguilar Feijó es Decano de la Facultad de Ciencias Económicas y Administrativas, y Docente Titular de la Universidad de Cuenca (Ecuador). Economista. Máster en Gerencia de Proyectos. Máster en Economía con mención en Finanzas. Estudiante de Doctorado en Ciencias de la Administración, Universidad Nacional del Sur (Argentina).

Recibido: 17/06/2015

Aceptado: 30/12/2015 